\title{
Virtual 3D Campus Modeling by Using Close Range Photogrammetry
}

\author{
Surendra Pal Singh ${ }^{1, *}$, Kamal Jain ${ }^{1}$, V.Ravibabu Mandla ${ }^{2}$ \\ ${ }^{1}$ Department of Civil Engineering, Indian Institute of Technology-Roorkee, Roorkee, Uttrakhand, India \\ ${ }^{2}$ School of Mechanical \& Building Science, Vellore Institute of Technology(VIT) University, Vellore, Tamilnadu, India \\ *Corresponding author: surendra.geomatics@gmail.com
}

Received October 05, 2013; Revised November 24, 2013; Accepted December 13, 2013

\begin{abstract}
Virtual 3D modeling is a very important and hot topic for researchers of Geomatics. Many scientists are working in this direction. All over the world, so many educational institutes are available with its own campus. Campus is the land on which Institute; College or University buildings are situated. In the modern digital era, the demand of 3D Campus is increasing. Virtual 3D model of campus gives a good and photo-realistic appearance. In Geomatics market, So many image based techniques are available for 3D modeling. Photogrammetry and Laser scanning are the main Geomatics techniques. Satellite Photogrammetry and Aerial Photogrammetry is not easy to use by every person, because the images are not easily available for everybody. Due to this a new approach is possible to make virtual 3D Campus. Close Range Photogrammetry is very easy to use. Images are easy to obtain by any handheld digital camera. Cost and Time is main key issue for this. In this paper, we are giving a simple and cheapest solution to create virtual 3D campus of any educational institute by using simple photographs based on Close range Photogrammetry. In this study, we used simple digital images obtained by a Hand held digital camera. This paper will describe the introduction, methodology, advantages, drawbacks and limitations of this method. In this study, we used the study area, Campus of Department of Civil Engineering, Indian Institute of Technology, Roorkee, (Uttrakhand), India. From this study, we find out the height and length of building of Civil Engineering department. The result of this study is also within the permissible limit and acceptable. It is a significance study for 3D modeling by using Close Range Photogrammetry. This 3D campus model can be exported in various other formats for various applications. These 3D models can be exported to Google Earth also. These 3D campus models can also be published on the website of that Institute or University.
\end{abstract}

Keywords: Geomatics techniques, camera calibration, Close range Photogrammetry, virtual 3D model

Cite This Article: Surendra Pal Singh, Kamal Jain, and V.Ravibabu Mandla, "Virtual 3D Campus Modeling by Using Close Range Photogrammetry.” American Journal of Civil Engineering and Architecture 1, no. 6 (2013): 200-205. doi: 10.12691/ajcea-1-6-9.

\section{Introduction}

Photogrammetry is an appropriate tool to provide information about man-made objects, vegetation cover and the like [4]. Three dimensional modeling of objects and scenes is an intensive and long lasting research problem in the computer graphic, Computer vision, and photogrammetric communities [5], and Due to the complexity of natural scenes and the lack of performance of image understanding algorithms, the fully automated methods cannot guarantee results stable and reliable enough for practical use.

C. Armenakis and G.Sohn, [3] also create a 3D model for York University campus. They use the images and aerial photos to create virtual campus. iCampus is part of the 50th year anniversary celebration of York University. The main aim of this project is to generate a virtual 3D model of York's Campus. For this project, they use the Airborne and terrestrial image with Lidar data and they create the $3 \mathrm{D}$ shapes of prominent man-made and natural terrain objects. iCampus project also investigates existing and new methods for buildings, trees and terrain reconstruction and for the photorealistic texture mapping on the reconstructed objects and surfaces.

Anuar and Lawali [1], produce a virtual 3D campus model of University of Technology, Malaysia (UTM), by using photogrammetric data. They use 3D digitization from stereo-photos.

Singh et al. [6], design and develop a multi-camera setup. They also develop a method for multi camera calibration. This is a very good product for photogrammetric data acquisition for Close range Photogrammetry.

Paul E. Debevec et.al., [13], also develop a method for 3D modelling from images and make a 3D model of Taj Mahal.

Shashi and Jain, [10], Singh et.al., [7] also discuss about 3D building modelling from Close range Photogrammetry. Shashi and Jain [11], also discuss about the use of digital camera for Close range Photogrammetry.

Zulkepli Majid et.al., [16], also create and discuss about 3D campus modelling by using Laser scanner. 
In Ref. [8] explains about Virtual 3D City modeling techniques and Applications.

Singh et.al., [9], also create an image based 3D model of campus. It is also a very cheap and simple method to create 3D model of campus. But it is less advance model than Photogrammetry.

Recently, 3D models are using in Navigations with 3D Maps, and anyone can use these model on mobile devices. At the end, these 3D models can be published on internet for civilian users. [15], and can be used in Cell-Phone, so all city will be in your hand. Thus, Geomatics techniques are playing a key role to create virtual 3-D models.

The needs for 3-D models (Fly-through model \& Walkthrough model) are growing an expanding rapidly in various fields. These virtual 3-D models are useful for planning in Navigation, Tourism, Disasters Management, Transportations, Municipality, Urban and Environmental Managements and Real-estate industry, so the generation of Virtual 3-D models is a most interesting research topic in recent years.

All of the above works have some advantages and some drawbacks. 3D model form Satellite images and Aerial images are very costly and not easily available to everybody. In these images, street view will not create properly. Laser scanning of campus is also not economically fit for all users.

Aerial Photography is mostly restricted in India, so aerial images are not easily available. Satellite images and Laser scanning is also not cost effective for virtual 3-D model generation. Therefore 3-D model generation is not an easy task in India. There are various methods available to create 3-D model for different applications. For Virtual 3-D model generation, method should be such as that the whole 3-D model can be generated in minimum time with minimum labour work and low cost. The traditional method of 3-D model generation is time consuming, laborious, and not so accurate.

So, we approached a new method to create Virtual 3D model of a campus by using Close range photogrammetric method. Measurements are also possible in this method. Result of height and length of building is within the permissible limit and acceptable. Texture is also good. Close range Photogrammetry is a good option and can use easily for any 3D model generation. So, in my this research work, I used approach for 3D model generation by using Close Range Photogrammetry techniques. This method produced accurate Photo-realistic model in minimum time and minimum labour work with less cost. It has good accuracy also.

In this study, we make the 3D model of Department of Civil Engineering, Indian Institute of Technology; Roorkee, India. We make this department by using Photomodeler; an image based 3D modeling software that works on Close Range Photogrammetric principles. Images are taken from a Sony Cybershot HX7V digital camera.

\section{Methodology}

Camera Calibration, Image acquisition from Hand held Digital Camera, Processing of images, wire frame model creation, and Photorealistic 3-D Building model generation are the main steps for this work.
These steps can be explained as: [7]

1. Create a calibrated or approximate camera description,

2. Plan the Measurement Project,

3. Take photographs of the object or scene,

4. Import the photographs

5. Mark features (e.g. points, shapes etc.) on the photos,

6. Identify which points are the same,

7. Process the data, and

8. Export the resulting 3D data to a CAD or graphics program.

The flow diagram of the methodology can be shown as given below:

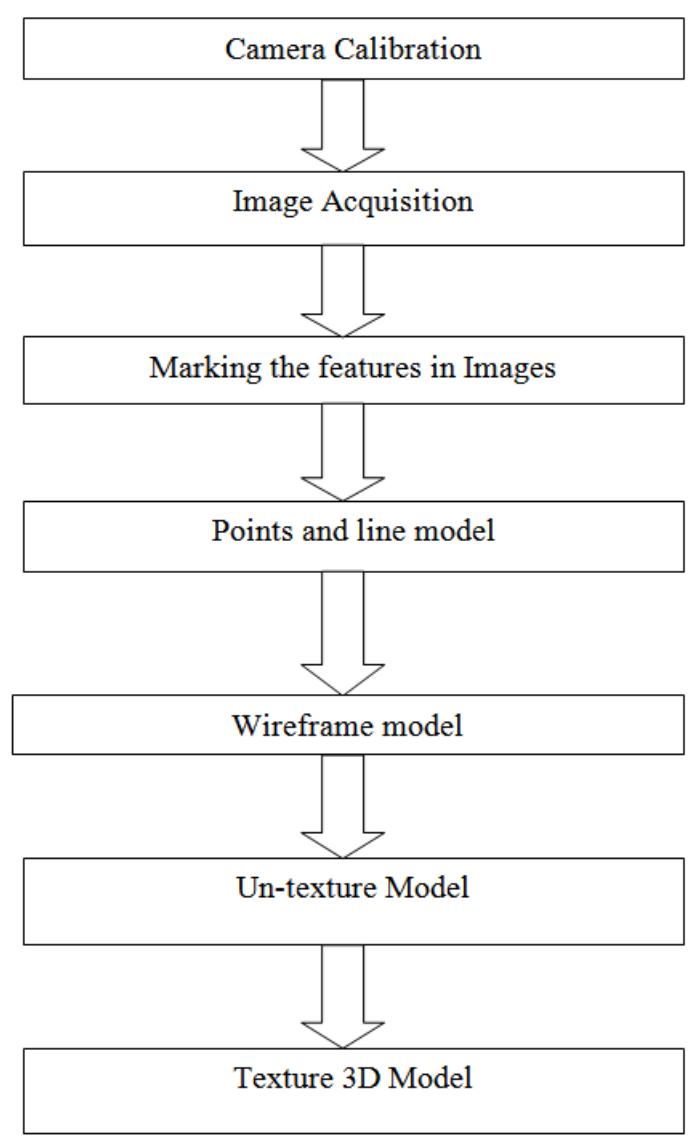

Figure 1. The flow diagram of the methodology

\subsection{Camera Calibration}

Camera Calibration is also important for any close range Photogrammetry work. It is a process of determining the characteristics of a camera so it can be used as a measurement device. These characteristics specifications of camera are focal length of the lens (f), CCD format size of a digital camera ( $F w, F h$ ), the Principal points (Xp,Yp), and Lens distortions (k1,k2,k3, and p1, p2). This description needs to be created only once and is used for every subsequent project done with this camera.

For this study, we used Sony Cybershot HX7V digital camera, (Figure 2). The calibration of the Sony Cybershot HX7V digital camera was performed using Photomodeler 6 in self calibration module, using several images of a Calibration Grid, supplied with the software.

The Calibration Grid is a pattern of dots specifically designed for the Camera Calibrator. After processing of this calibration grid images, camera parameters obtain. 
These camera parameters are Focal length of lens, Format size, Image size, Principal points (Xp,Yp), and Lens distortions parameters (k1, k2, k3, and p1, p2).

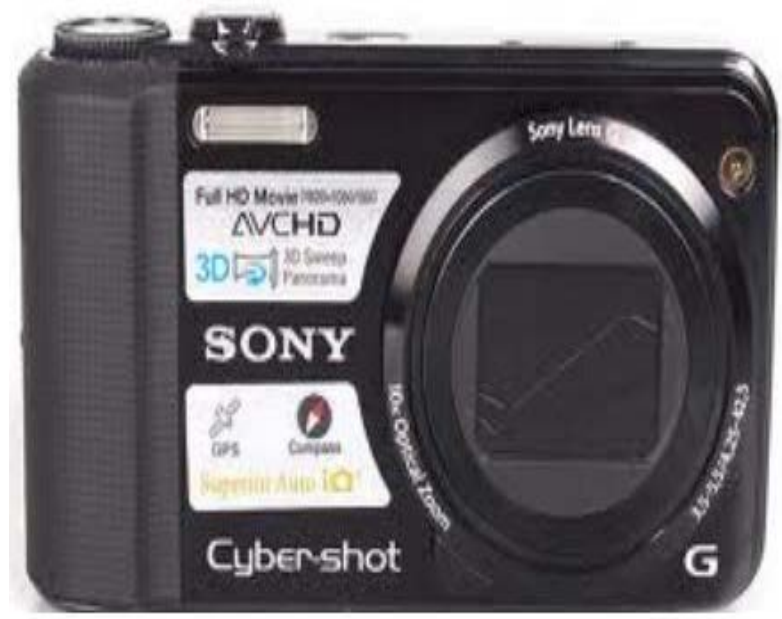

Figure 2. Sony DSC HX7V Camera used for Image Acquisition

A result of camera calibration is showing in Table 1.

Table 1. Shows the result of camera calibrations

\begin{tabular}{|c|c|}
\hline Camera parameters & Sony DSC HX7V \\
\hline Focal length (f) (mm) & 4.6661 \\
\hline Format size (mm) & $\mathrm{Fw}=6.0000$ \\
(F-width, F-hight) & 3.0000 \\
\hline Principal point $(\mathrm{Xp})(\mathrm{mm})$ & 2.2500 \\
\hline Principal point(Yp) $(\mathrm{mm})$ & $0.000 \mathrm{e}+000$ \\
\hline Lens distortions $\mathrm{k} 1$ & $0.000 \mathrm{e}+000$ \\
\hline Lens distortions $\mathrm{k} 2=\mathrm{k} 3$ & $0.000 \mathrm{e}+000$ \\
\hline Lens distortions $\mathrm{p} 1$ & $0.000 \mathrm{e}+000$ \\
\hline
\end{tabular}

\subsection{Study Area}

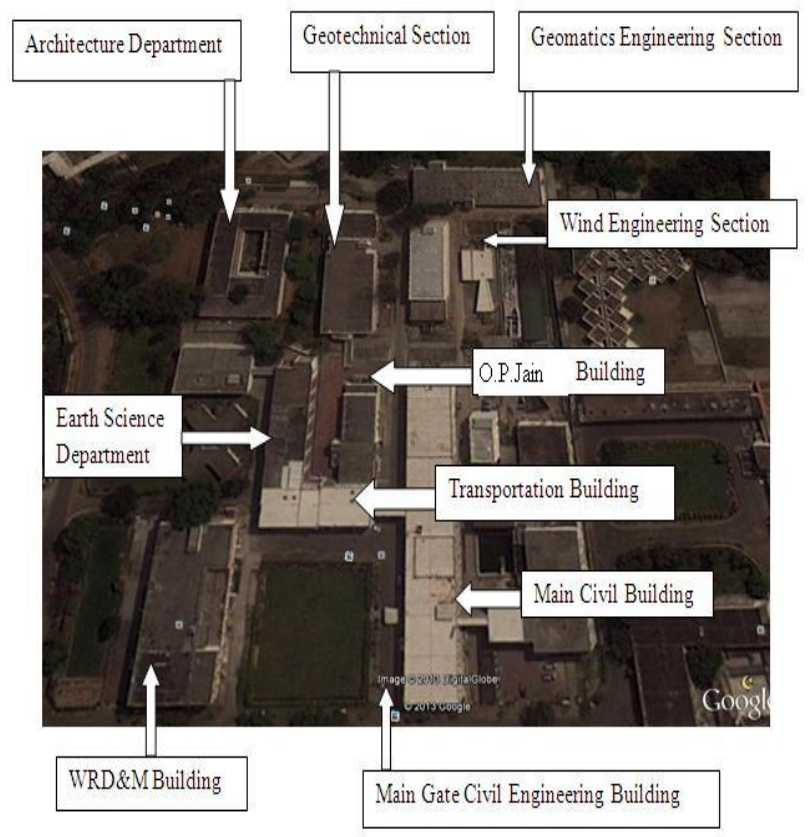

Figure 3. Department of Civil Engineering, IIT-Roorkee, India (Source: Google Earth, June2013)
The Civil Engineering Department has surrounding by Department of Architecture, Department of Water Resources Development and Management (WRD\&M), and this Civil Engineering Department has the following main sections and buildings: Geomatics Section Building, Geotechnical Section Building (having CAD Lab and Research Scholar Wing), Lecture Hall building (having Newton Room and Reyleigh rooms), Wind Engineering Section, O.P. Jain auditorium building, Transportation building, Main Civil building, and Hydraulics building. The Department of Civil Engineering is showing in Figure 3.

\subsection{Image Acquisition}

After calibration of the camera, it was ready to take photographs. For Any ideal close range photogrammetric work, the base line/distance ratio ie., the distance between two camera positions while taking photographs to the distance between the camera to the object ratio should be within reasonable limits. It should not be too small. The values of this ratio should be between $1 / 15$ and $1 / 20$. If the building façade is large, then camera is kept at large distance from the building. [2].

For any Close range Photogrammetric project, the photos should be taken according to; "3X3 rules”, given by Waldhausl and Ogleby, 1994, [14] and explained by Shashi and Jain, [11]. These rules are best suitable for any close range photogrammetric image acquisition with amateur cameras.

\subsection{Processing of Images}

After loading the images, we mark the similar points in corresponding images. Based on Stereophotogrammetric principles [12], it will calculate and make a 3D point in space.

It will also calculate the camera positions for projects. The all camera positions can be seen in the Figure 4 .

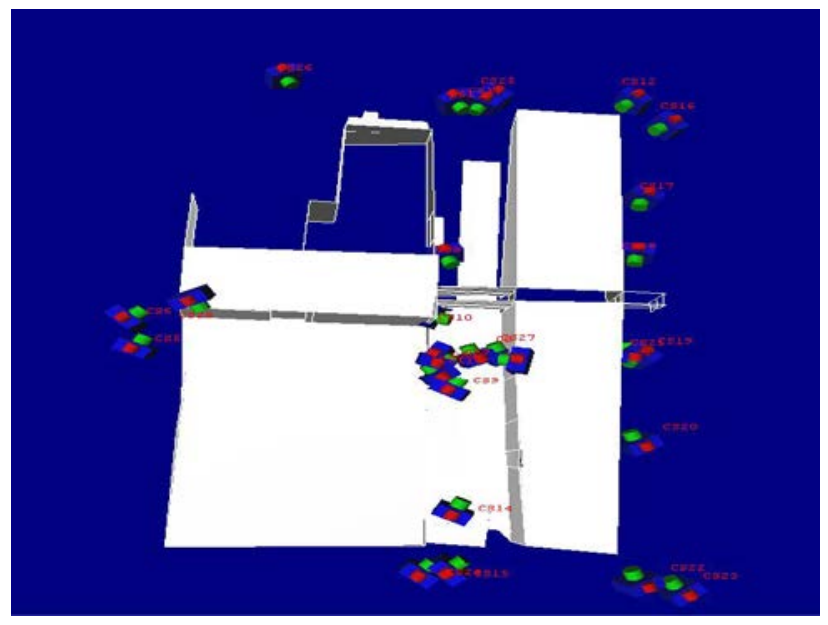

Figure 4. Positions of camera during data acquisition

A 3D model without surfaces or textures is called as a Wireframe model. The wireframe model represents the building as a quantity of vertices and edges. This representation is true if anyone is interested in the general form of the building.

Figure 6, shows the Wireframe 3D model of the Civil Engineering Department building, and Figure 7, showing the 3D model of Civil Department (without texture). 


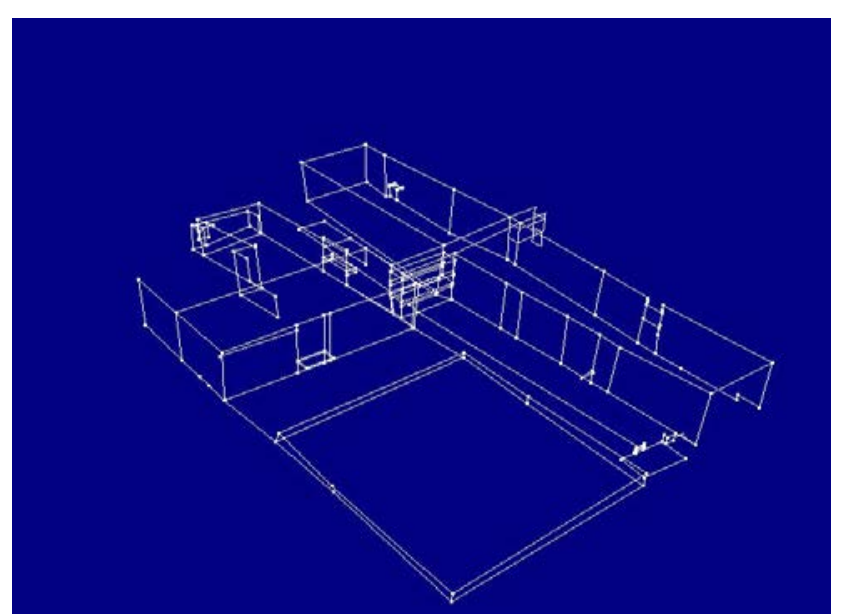

Figure 5. Photogrammetric Points \& lines model of Civil Engineering Department

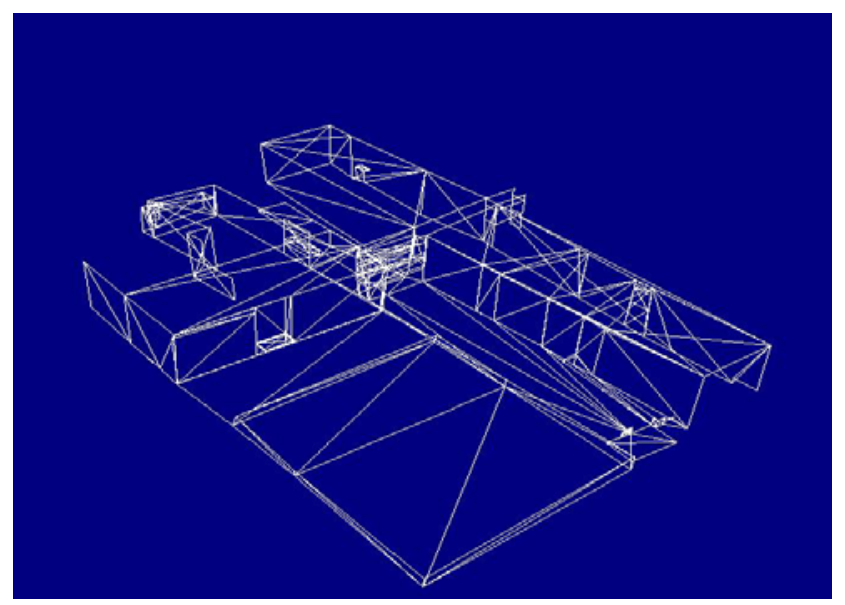

Figure 6. 3D wireframe model of the Civil Engineering Department

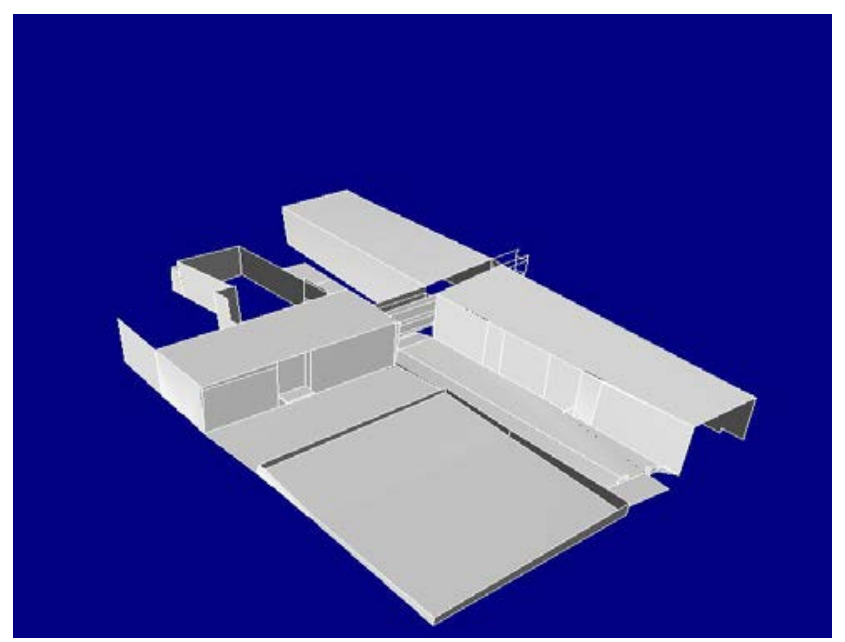

Figure 7. 3D model without texture

\subsection{Software Used}

We use software Photomodeler 6, [17]. This software is developed by EOS Company in Canada and released in 1993. It is a first commercial digital Close Range Photogrammetry (CRP) and image based modeling software. There is two kind of product: Photomodeler and Photomodeler Scanner (PMS). Photomodeler Scanner has all functions of Photomodeler. PMS also have the Smart Match, Scanning and Dense Surface Modeling (DSM) functions.
It works for Image based modeling by using Close Range Photogrammetric principles. Close range Photogrammetry used for distance between object and camera is less than $300 \mathrm{~m}$. In CRP, most of the photographs are taken from the ground. This software used for measurement and modeling in archaeology, architecture, biology, engineering, film production, forensics, and mining based on Close Range Photogrammetry.

\subsubsection{Main Features of Photomodeler}

1. It creates CAD like product.

2. It has the accurate measurement capabilities.

3. It can also model a man made shape of any object.

4. It can export the 3D model to other formats for other applications.

5. Automatic marking is also possible.

\section{Result and Discussion}

By this Image based Close range Photogrammetric study, we obtained a Photorealistic Virtual 3D model of Department of Civil Engineering, Indian Institute of Technology, Roorkee, (IIT-R), India, (Figure 8) is obtained.

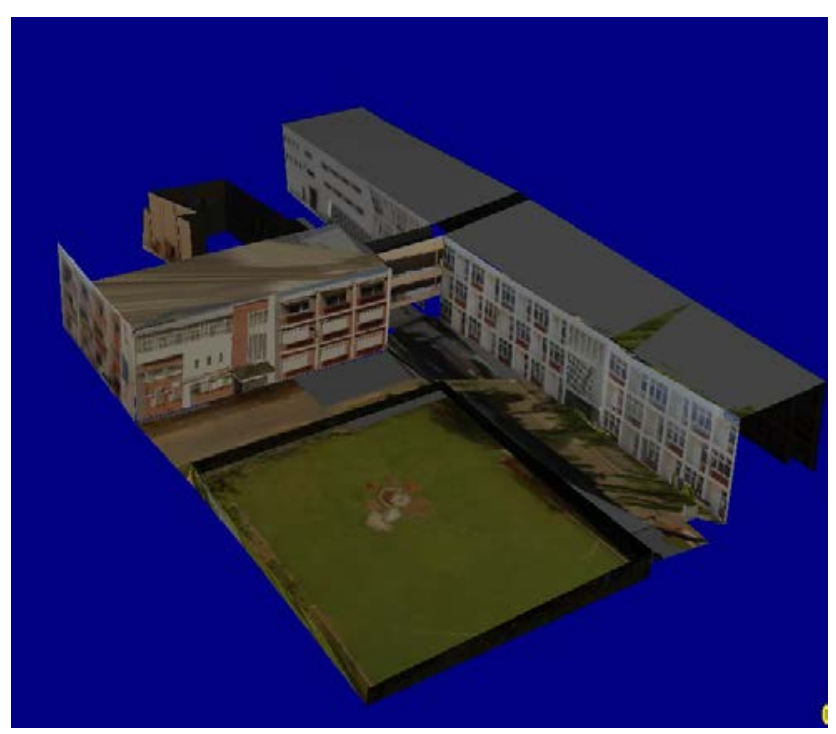

Figure 8. Virtual 3-D Photo-realistic Textured model of Department of Civil Engineering, IIT-Roorkee

This 3D model is measurable and having very good accuracy.

This 3D model can be exported into 3D DXF (.dxf), 3D studio (.3ds), VRML (.wrl), Wavefront (.obj), Rhino (.3dm), MayaScript (.ma), Google Earth (.kml and.kmz), Maxscript (.ms), FilmBox (.fbx) for further useful various applications.

We generate a Photorealistic street view of Department of Civil Engineering, IIT-Roorkee campus. It gives a realistic look for a model. It also covers more details of façade.

Texture quality depends on camera quality. High resolution of camera gives better textured model.

This virtual 3-D building model is very useful and an important component to create a full Virtual 3-D City model. This is also useful for Architecture and Urban 
Planning, Archeology, Virtual tourism, Building Information Modeling (BIM), Simulation, Restoration of Buildings etc.

\subsection{Accuracy Check}

The accuracy depends on the following factors:

1. Camera calibration quality- Calibration is the process of determining the camera's focal length, format size, principal point, and lens distortion.

2. Resolution of camera- Higher resolution of image gives better results.

3. Geometry of Camera position- the camera positions have good spread will provide the best results

4. Marking of features on image- Due to human interaction, marking of pint may be not accurate. So it will affect the accuracy of project.

To check the accuracy of the model, we use a method. In this method two distances are measured in the model created from images and its lengths is compared with the ratio of same lengths in the model created with the image.

For the main building of Civil Engineering department of the Indian Institute of Technology Roorkee, distances of sides of the walls are measured using the Tape.

In all the cases, the distances match with the field measurement and the model measurement. This implies that the developed model is much suitable for the 3D City modeling.

The accuracy result is showing in the Table 2.

\begin{tabular}{|c|c|c|c|}
\hline Building detail & $\begin{array}{c}\text { Tape } \\
\text { measurement } \\
\text { (m) }\end{array}$ & $\begin{array}{c}\text { Model } \\
\text { measurement } \\
(\mathrm{m})\end{array}$ & $\begin{array}{l}\text { Difference } \\
\text { (m) }\end{array}$ \\
\hline $\begin{array}{l}\text { Civil Engg. Main } \\
\text { Building Length }\end{array}$ & 112.75 & 112.72 & 0.03 \\
\hline $\begin{array}{l}\text { Civil Engg. Main } \\
\text { Building Width }\end{array}$ & 18.10 & 18.35 & 0.25 \\
\hline $\begin{array}{l}\text { Civil Engg. Main } \\
\text { Building Height }\end{array}$ & 11.80 & 11.57 & 0.23 \\
\hline Bridge Length & 13.10 & 13.28 & 0.18 \\
\hline Bridge Width & 4.00 & 3.80 & 0.20 \\
\hline
\end{tabular}

The accuracy of model is within acceptable limit. The error is possible due to incorrect marking on photos.

\section{Conclusion}

This Image based photogrammetric technique is very useful to create virtual 3D City modeling, because in some area aerial images and satellite images are not easily available, but camera images are easily available. The cost and accuracy is also very good. By using this method, anyone can create virtual 3D model for various applications. In this way, we can conclude: “The Close range Photogrammetry is a good and low cost tool to create photorealistic 3-D Model of a building”. The accuracy of model is within acceptable limit. The error is possible due to incorrect marking on photos.

We can also discuss about some advantages and Limitations of this method. Following are the main advantages and Limitation of this method;

\subsection{Advantage}

- Any camera can be used.
- Different kind of camera can also be used in a same project.

- It gives the best measurement accuracy.

- Export facility is also useful for further applications.

\subsection{Limitations}

- It requires lot of experience in Photogrammetry.

- Finding an appropriate situation of cameras would be the most sensible part.

- Photography taken for Photomodeler is also need experience.

- The mathematical model that used in solving photogrammetric parameters is complex.

- Establishing an excellent situation for exterior view of building could be solved regularly but for the interior side of a building we encountered with some limitations.

- Camera calibration is also necessary.

- Roof texture will not come accurate.

Thus we can say this technique will be very useful to make virtual model of any Campus. This technique is very cost effective to create virtual 3D Campus model, compare to laser techniques. Based on this method, we can also make a Virtual 3D City model. In absence of Satellite Images and Aerial Images, this method is most suitable for 3D modeling. Due to low cost, this method is also suitable then Laser scanning.

The purpose of this paper is to develop the concept for Image based 3D modeling by using Close Range Photogrammetry. It will act as a bridge between Photogrammetry and institutes, societies as well as people who take pictures not only for holiday memories but these photos can be useful for practical or scientific purposes.

This Image based 3D modeling work will be also useful for Civil Engineering and Architecture community.

\section{Acknowledgment}

This work was supported by the MHRD grant (also called as Institute Fellowship; duration From Jan.-2009 to Dec.-2012) given by Indian Institute of Technology, Roorkee, Uttarakhand, India. Also thanks to my friends and staff of Civil Engineering Department of IIT-Roorkee for support us during this work.

\section{References}

[1] Anuar Ahmad, Lawali Rabiu, "Generation of Three Dimensional Model of Building using Photogrammetric Technique”, IEEE, 7th International Colloquium on Signal Processing and its Applications, 2011.

[2] Badekas, John, "Photogrammetric Surveys of Monuments and Sites”, International Symposium on Photogrammetric Surveys of Monuments and Sites. Amsterdam, Ed.1975.

[3] C. Armenakis and Gunho Sohn, “i Campus: 3D Modeling of York University Campus”, ASPRS 2009 Annual Conference, Baltimore, Maryland, March 9-13, 2009.

[4] Gruin, A., Wang, X., "CyberCity Modeler: a tool for interactive 3D city model generation”, Photogrammetric week Wichmann, Karlsruhe, 1999.

[5] Remondino, Fabio, and Sabry El-Hakim., "Image based 3D Modelling: A Review”, The Photogrammetric Record, 21, 115, 269-291, 2006.

[6] Singh, Surendra Pal, Jain, Kamal, Mandla V. Ravibabu, "Design and Calibration of Multi Camera setup for 3D City modeling”, 
International Journal of Engineering Research \& Technology (IJERT), Vol. 2, Issue 5, May-2013.

[7] Singh, Surendra Pal, Jain, Kamal, Mandla V. Ravibabu, "3-D Building Modeling from Close Range Photogrammetry", International conference in Geomatrix-12, CSRE, Indian Institute of Technology-Bombay, India, Feb 26-29,2012.

[8] Singh, Surendra Pal, Jain, Kamal, Mandla V. Ravibabu, "Virtual 3D City modeling: Techniques and Applications", 3D GeoInfo 2013, 8th 3D GeoInfo Conference, ISPRS WG II/2 Workshop, "Advances in Multi-scale and multi-dimensional modeling and data representation”, Istanbul, Turkey, 27-29 November, 2013.

[9] Singh, Surendra Pal, Jain, Kamal, Mandla V. Ravibabu, “ Image Based 3D Modeling of Campus (Department of Civil Engineering, IIT Roorkee, Uttarakhand, India) by Using SketchUp”, International Journal of Advanced Civil Engineering and Architecture Research, Volume 2, Issue 1, pp. 65-71, Article ID Tech-168, 2013.

[10] Shashi, M. and Jain, Kamal, "Use of Photogrammetry in 3D Modeling and visualization of buildings", Asian Research Publishing Network (ARPN) - Journal of Engineering and Applied Sciences. Vol. 2, No. 2, April, 2007.

[11] Shashi M. and Jain, Kamal, "Use of Amateur camera in Architectural Photogrammetry”, Map World Forum, Hyderabad, India, 2007.
[12] Stancik,P., "Principle of Streophotogrammetry-3D Point coordinates reconstruction”, conference a soutěže Student EEICT 2004.

[13] Paul E Debevec., et al, "Image-based modeling and rendering of architecture with interactive photogrammetry and view-dependent texture mapping", Proceedings of the IEEE International Symposium on Circuits and Systems, Volume 5, 31 May-3 June, pp 514-517, 1998.

[14] Waldhäusl P., Ogleby C.,”3 x 3 Rules for simple photogrammetric documentation of architecture”, In: J.G.Fryer (Editor), International Archives of Photogrammetry and Remote Sensing, Part5, pp 426-429, 1994.

[15] Zlatanova, S., Tempfli, K., "Modelling for 3D GIS:Spatial Analysis and Visualization Through The Web", IAPRS, Vol. XXXIII, Amsterdam, 2000.

[16] Zulkepli Majid, Halim Setan, Mohamad Ghazali Hashim, Julian Goh, "3D Campus Modeling using Terrestrial Laser Scanning Technology -First Experience in Malaysia”, 3D Geoinfo 2008, Seoul, KOREA, 13-14 November 2008.

[17] Photomodeler (http://www.photomodeler.com). 